\title{
Development of Negative-type Photosensitive Semi-alicyclic Polyimide using a Photobase Generator
}

\author{
Katsuhisa Mizoguchi, Yuji Shibasaki and Mitsuru Ueda* \\ Department of Organic and Polymeric Materials, Graduate School of Science and Engineering, \\ Tokyo Institute of Technology, 2-12-1, O-okayama, H-120, Meguro-ku, Tokyo 152-8552, Japan \\ ueda.m.ad@m.titech.ac.jp
}

A negative-type photosensitive polyimide (PSPI) based on a semi-alicyclic poly(amic acid) (PAA) and a photobase generator (PBG), \{[(4,5-dimethoxy-2nitrobenzyl)oxy]carbonyl 2,6-dimethyl piperidine (DNCDP) has been developed. PAA was readily prepared from cyclobutane-1,2,3,4-tetracarboxylic dianhydride (CBDA) and 4,4'-oxydianiline (ODA) in $N, N$-dimethylacetamide (DMAc) at room temperature, and used directly by the addition of the PBG for photolithography. The PSPI consisting of PAA $(85 \mathrm{wt} \%)$ and PBG (15 wt\%) showed the high sensitivity of $53 \mathrm{~mJ} / \mathrm{cm}^{2}$ and contrast of 39.5 , respectively, after exposed to 365 $\mathrm{nm}$ UV light (i-line) and developed with $0.238 \mathrm{wt} \%$ tetramethylammonium hydroxide aqueous solution (TMAHaq) as a base-developer. A fine negative pattern with $6 \mu \mathrm{m}$ features on a silicon wafer was obtained by a contact-printing mode and converted into a PI pattern by heating at $200^{\circ} \mathrm{C}$.

Keywords: polyimides / photoresist / photosensitive polymer / photobase generator

\section{Introduction}

PSPIs have been utilized in a variety of electronic devices such as insulators, buffer coatings and passivation layers because of their excellent thermal, electrical and mechanical properties. In addition, they are also attractive because they simplify the pattern-formation processes and avoid the use of additional photoresists in the microelectric industry. ${ }^{1-5}$

A widely used negative-type PSPI is a poly(amic ester) (PAE) having a methacrylate unit, which is prepared in two step reaction. The reaction of a tetracarboxylic dianhydride with 2 hydroethylmethacrylate produces a corresponding diester-dicarboxylic acid, which is then reacted with a diamine in the presence of a condensing agent to produce the PAE. Thus, this synthesis requires a tedious and expensive process, and it is important to develop a direct PSPI formulation method. To remedy this problem, in a preceding paper, ${ }^{6}$ we reported a direct formulation of PSPI based on a aromatic PAA and DNCDP as a PBG. This photoresist showed a relatively high photosensitivity of $220 \mathrm{~mJ} / \mathrm{cm}^{2}$ and a contrast of 11.7 , respectively.

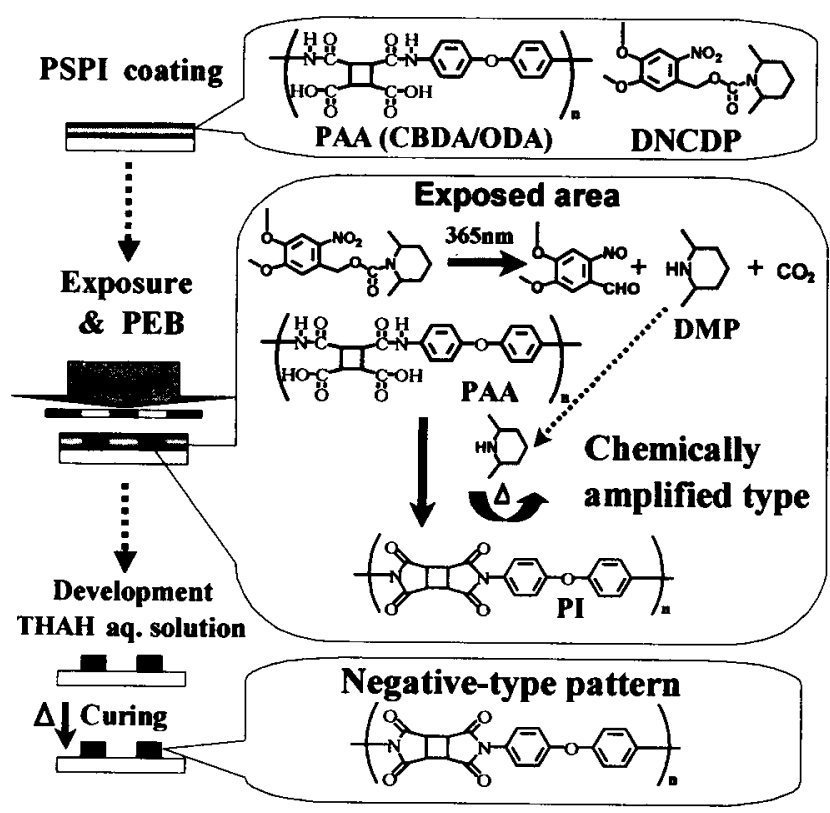

Scheme 1. Patterning process of negative-type PSPI.

To expand the utility of this method, we applied it to the development of photosensitive semialicyclic polyimide (PSSAPI). 
This report describes the successful development of an alkaline-developable, chemically amplified negative-type PSPI based on a semi-alicyclic PAA and a PBG.

The formulation of PSSAPI is simple, involving the addition of DNCDP to the polymerization solution of CBDA and ODA. The PSSAPI solution is spin-coated and baked in the usual way. Then, the film is exposed to UV light to produce 2,6dimethylpiperidine from DNCDP. Upon postexposure baking (PEB) treatment of the PSSAPI film, 2,6-dimethylpiperidine catalyzed the imidization of the semi-alicyclic PAA. The dissolution rate of the exposed area to TMAHaq decreases, and a negative image is provided. As a consequence, the direct formulation of chemically amplified PSSAPI simplifies the photolithographic process (Scheme 1).

\section{Experimental}

\subsection{Materials}

ODA was recrystallized with tetrahydrofuran (THF) under nitrogen. CBDA was kindly donated by JSR corporation. The CBDA dried for $12 \mathrm{~h}$ at $150{ }^{\circ} \mathrm{C}$ in vacuo was used. DNCDP was prepared according to the reported procedure in a $75 \%$ yield after recrystallization from cyclohexane / hexane. ${ }^{7}$ Melting point: $139.2{ }^{\circ} \mathrm{C}$ (literature: $122-124{ }^{\circ} \mathrm{C}$ ). Anal. Calcd. for $\mathrm{C}_{17} \mathrm{H}_{24} \mathrm{~N}_{2} \mathrm{O}_{6}: \mathrm{C}, 57.94 \% ; \mathrm{H}$, $6.86 \%$;, $7.95 \%$; O,27.24 \%; Found: C, $58.09 \%$;, $6.92 \%$; N, $7.87 \%$; O, $27.12 \%$. The $0.238 \mathrm{wt} \%$ TMAHaq was used as a base developer. $N, N$-dimethylacetamide (DMAc) was distilled under reduced pressure over calcium hydride and stored over 4-A molecular sieves. Other reagents and solvents were obtained commercially and used as received.

\subsection{Synthesis of PAA (CBDA/ODA type)}

CBDA was added at one time to a ODA solution in DMAc with strring at $3 \sim 5{ }^{\circ} \mathrm{C}$ in an ice water bath for $10 \mathrm{~min}$ as shown in Table 1 .

Then, the mixture was stirred at room temperature for $17 \mathrm{~h}$ to give a viscous clear solution. The yields were quantitative. Inherent viscosities of those polymers were $2.47,1.67$ and $0.92 \mathrm{dl} / \mathrm{g}$ at a concentration of $0.5 \mathrm{~g} / \mathrm{dl}$ in DMAc at $30{ }^{\circ} \mathrm{C}$.
Table 1. Synthetic conditions of PAA.

\begin{tabular}{lccc}
\hline $\begin{array}{l}\text { CBDA : ODA } \\
\text { (molar ratio) }\end{array}$ & $\begin{array}{c}\text { CBDA } \\
(\mathrm{mmol} ; \mathrm{g})\end{array}$ & $\begin{array}{c}\text { ODA } \\
(\mathrm{mmol} ; \mathrm{g})\end{array}$ & $\begin{array}{c}\text { DMAc } \\
(\mathrm{ml})\end{array}$ \\
\hline \hline (1) $1.00: 1.00$ & $3.00 ; 0.588$ & $3.00 ; 0.601$ & 7.19 \\
(2) $1.02: 1.00$ & $3.06 ; 0.600$ & $3.00 ; 0.601$ & 7.27 \\
(3) $1.05: 1.00$ & $3.15 ; 0.618$ & $3.00 ; 0.601$ & 7.38 \\
\hline
\end{tabular}

2.3. Degree of imidization exposed and unexposed area

The polymer solution was diluted with DMAc to a concentration of $8.5 \mathrm{wt} \%$, followed by the addition of $1.5 \mathrm{wt} \%$ DNCDP. The solid content was $10 \mathrm{wt} \%$ in DMAc. This solution was spincoated on a silicon wafer, baked at $120{ }^{\circ} \mathrm{C}$ for 3 $\mathrm{min}$ in air. A half area of these films were exposed to $365 \mathrm{~nm}$ light (i-line) of $300 \mathrm{~mJ} / \mathrm{cm}^{2}$, and then, baked on a hotplate at $190{ }^{\circ} \mathrm{C}$ from $5 \mathrm{~min}$ to $1 \mathrm{~h}$. A reference PI film was prepared by heating at $120{ }^{\circ} \mathrm{C}$ for $3 \mathrm{~min}$, at $200,250{ }^{\circ} \mathrm{C}$ for $0.5 \mathrm{~h}$ and at $350{ }^{\circ} \mathrm{C}$ for $1 \mathrm{~h}$ in air, respectively. Absorption intensities on a FT-IR spectrum at $1381,1385 \mathrm{~cm}^{-1}$ $\left(A_{1381}, A_{1385}\right)$ assignable as the $\mathrm{C}-\mathrm{N}$ stretching of the imide group and at $1223,1234,1250 \mathrm{~cm}^{-1}\left(\mathrm{~A}_{1223}\right.$, $\left.A_{1234}, A_{1250}\right)$ assignable as the $\mathrm{C}-\mathrm{O}$ stretching of phenyl ether were measured, and the degrees of imidization were determined using the following equation (1)

\section{Imidization $(\%)=$}

$$
\begin{aligned}
& \left(A_{1381} / A_{1234 \text { (samp) }}-A_{1381} / A_{1223 \text { (init) }}\right) / \\
& \left(A_{1385} / A_{1250 \text { (imid) }}-A_{1381} / A_{1223 \text { (init) }}\right) \times 100
\end{aligned}
$$

Subscripts between parentheses following $A_{1381}$ $/ A_{1234}$ in the equation indicate states of the polymer films; e.g. (samp) is the polymer sampled at $190^{\circ} \mathrm{C}$ for each PEB time $(5 \sim 60 \mathrm{~min})$; (init) is initially prebaked PAA at $120{ }^{\circ} \mathrm{C}$ for $3 \mathrm{~min}$ in air; (imid) is the fully cured at $350{ }^{\circ} \mathrm{C}$ for $1 \mathrm{~h}$ in air.

\subsection{Photosensitivity}

A $1.0 \mu \mathrm{m}$ thick photosensitive polymer film was prepared by a $10 \mathrm{wt} \%$ solid content DMAc solution consisting of $85 \mathrm{wt} \%$ PAA, $15 \mathrm{wt} \%$ DNCDP, followed by spin-coating on a silicon wafer and then prebaked at $120{ }^{\circ} \mathrm{C}$ for $3 \mathrm{~min}$. This 
film was exposed to i-line using a filtered supperhigh-pressure mercury lamp, post-exposure baked (PEB) at $190{ }^{\circ} \mathrm{C}$ for $8.5 \mathrm{~min}$. A development of the exposed film was performed with $0.238 \mathrm{wt} \%$ TMAHaq at $25^{\circ} \mathrm{C}$ for $35 \mathrm{sec}$, rinsed in distilled water and dried with drier. The characteristic sensitivity curve was obtained by plotting a normalized film thickness against the exposure dose (unit: $\mathrm{mJ} / \mathrm{cm}^{2}$ ). Image-wise exposure was carried out in a contact-printing mode.

\subsection{Measurements}

The Fourier-transferred (FT-IR) and UV-visible spectra were recorded on Horiba FL-720, JASCO V-560 spectrometer, respectively. Viscosity measurements were carried out by using an Ostwald viscometer at $30{ }^{\circ} \mathrm{C}$ in DMAc. Thermogravimetric analysis (TGA) was performed on Seiko TG/DTA 6300 at a heating rate of $10^{\circ} \mathrm{C}$ $/ \mathrm{min}$ under a nitrogen stream. The film thickness on silicon wafer was measured by a Veeco Instrument Dektak ${ }^{3}$ surface profiler. Field emission scanning electron microscopy (SEM) was taken with a Technex Lab Tiny-SEM 1540 with $15 \mathrm{kV}$ accelerating voltage for imaging. $\mathrm{Pt} / \mathrm{Pd}$ was spattered on film in advance of the SEM measurement.

\section{Results and Discussion}

\subsection{Synthesis of semi-alicyclic PAA}
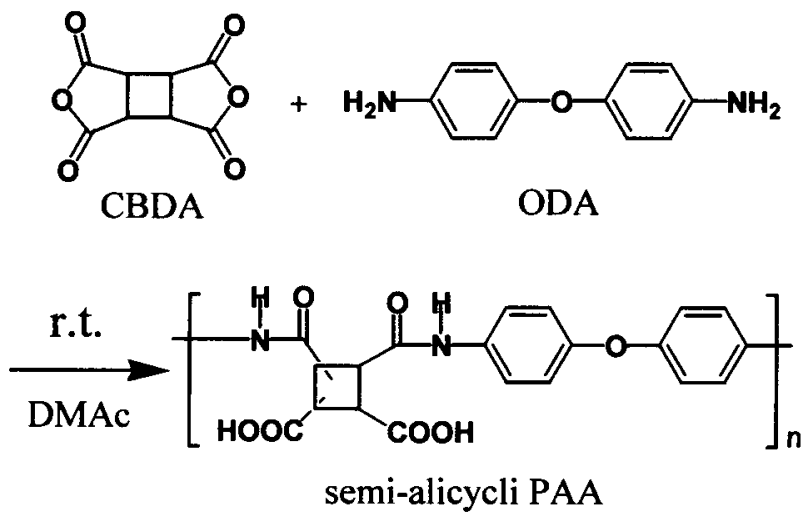

Scheme 2. Synthesis of the semi-alicyclic PAA.

As an alicyclic tetracarboxylic dianhydride and a diamine, CBDA and ODA were selected, respectively. The polymerization was carried out in DMAc at room temperature, giving PAAs with high inherent viscosities (Scheme 2, Figure 1).

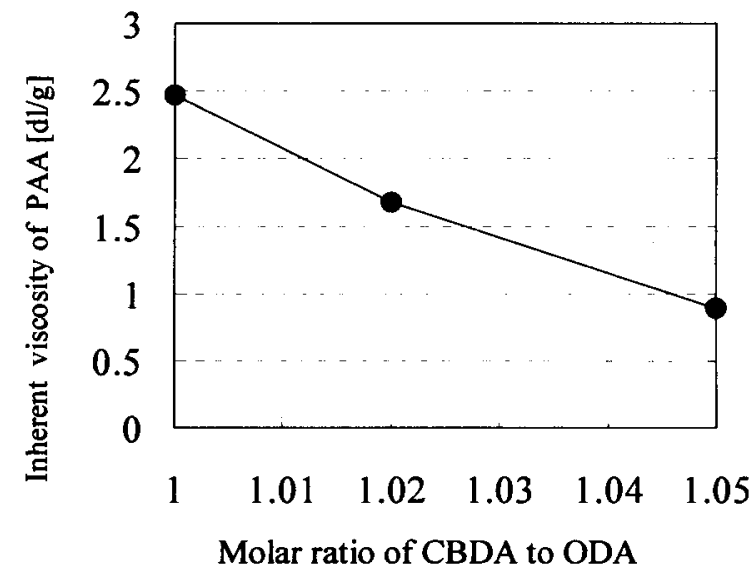

Figure 1. Inherent viscosities of PAAs.

The molecular weights of PAA influence the dissolution rate in TMAHaq. Thus, the molecular weight of PAA was controlled by changing the molar ratio of CBDA to ODA. The results are shown in Figure 1. The PAA having an inherent viscosity of $0.92 \mathrm{~g} / \mathrm{dL}$ was used for the lithographic evaluation and pattern formation because of an appropriate dissolution to $0.238 \mathrm{wt} \%$ TMAHaq.

\subsection{Properties of semi-alicyclic PI}

The semi-alicyclic PAA was converted to the corresponding PI by thermal treatment at $300{ }^{\circ} \mathrm{C}$ for $2 \mathrm{~h}$ in air. The thermal stability of semialicyclic PI was examined by TGA (Figure 2). A $10 \%$ weight loss temperature in nitrogen is at 469 ${ }^{\circ} \mathrm{C}$. This decomposition temperature is lower than that of wholly aromatic PIs. It is, however, enough for microelectronics applications.

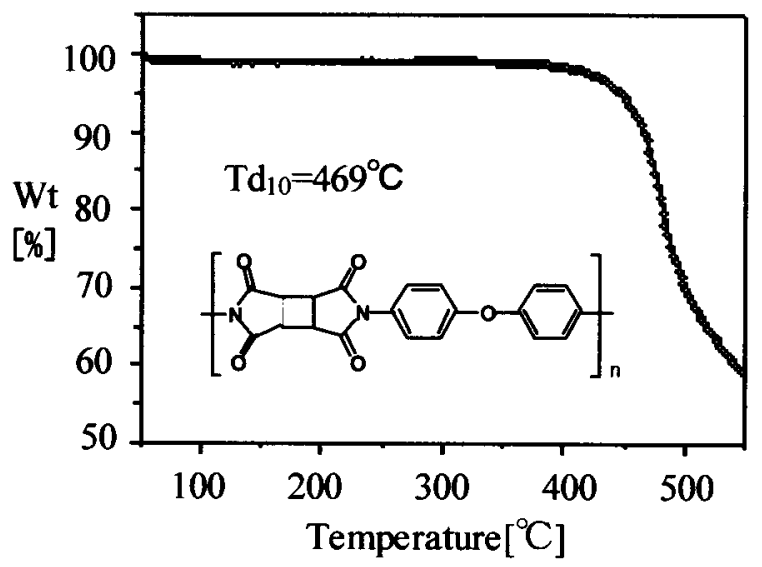

Figure 2. TG curve of PI (thermal treatment of PI; $300{ }^{\circ} \mathrm{C}: 2 \mathrm{~h}$ ). 


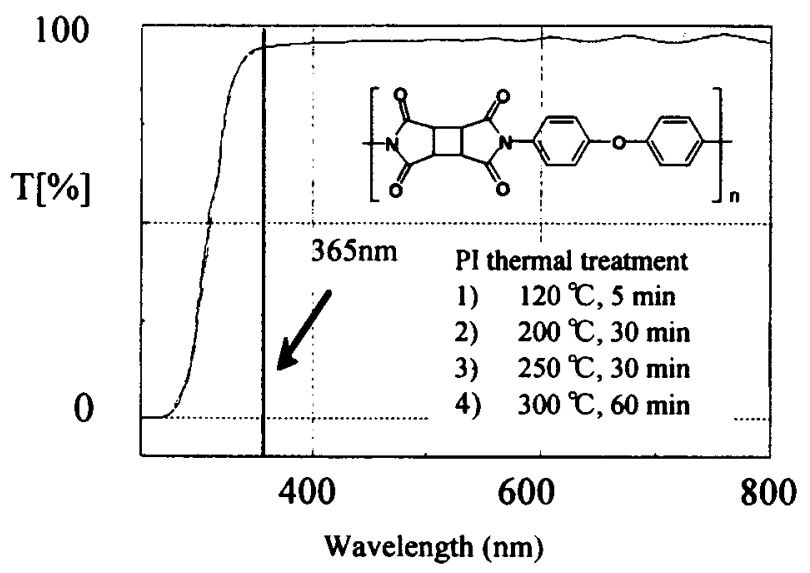

Figure 3. UV spectra of PI [film thickness on quartz plate : $1.4 \mu \mathrm{m}$ ].

Further characterization of UV-vis spectrometry (Figure 3) was performed for the semi-alicyclic PAA to measure its transparency, which is an important parameter to conduct i-line photolithography. The film with $1.4 \mu \mathrm{m}$ thickness shows high transparency in the $\mathrm{i}$-line region $(>90 \% \mathrm{~T})$.

\subsection{Lithographic Evaluation}

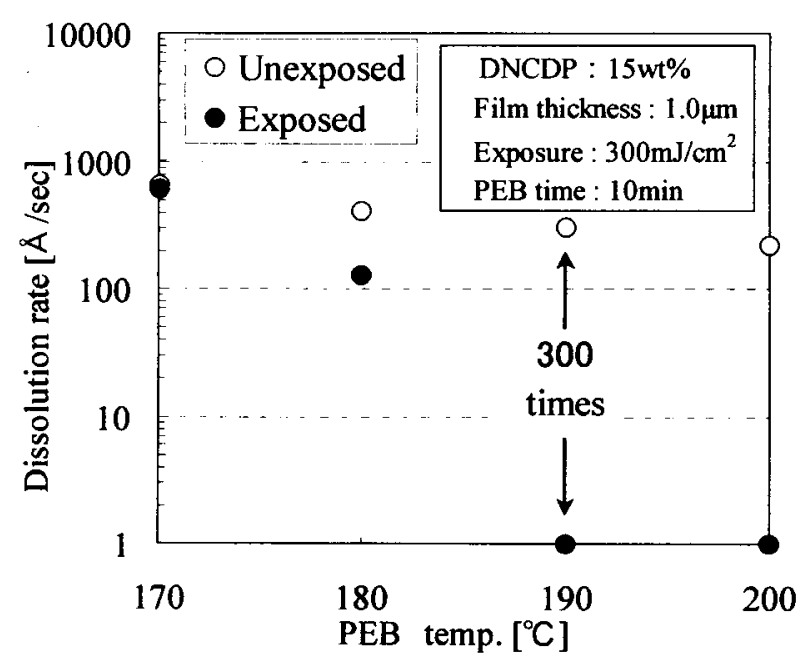

Figure 4. Effect of PBG temperature on the dissolution rate of the exposed and unexposed 1.0 $\mu \mathrm{m}$ PAA film containing $15 \mathrm{wt} \%$ DNCDP.

A PBG plays a key role in this patterning process. DNCDP, which has a strong absorption centered at $350 \mathrm{~nm}$ and allows using a $365 \mathrm{~nm}$ exposure, was chosen as a PBG. Moreover, the
DNCDP is a thermal stable PBG, and the thermal decomposition temperature is at around $200{ }^{\circ} \mathrm{C}(1$ and $5 \mathrm{wt} \%$ weight loss temperatures $\mathrm{Td}_{1}: 197$ and $\mathrm{Td}_{5}: 222{ }^{\circ} \mathrm{C}$, respectively).

To clarify the difference of dissolution behavior between the exposed and unexposed areas, the effect of the PEB temperature and the PEB time was studied by measuring the film thickness after development.

The films were spin-cast on silicon wafers from the diluted polymerization solution of $8.5 \mathrm{wt} \%$ PAA containing $1.5 \mathrm{wt} \%$ DNCDP (15 wt \% DNCDP to a total solid content) on silicon wafer, and then prebaked at $120^{\circ} \mathrm{C}$ for $3 \mathrm{~min}$ in air. These photosensitive polymer films were exposed to a filtered super-high-pressure mercury lamp ( $365 \mathrm{~nm}$, $300 \mathrm{~mJ} / \mathrm{cm}^{2}$ ), and then post-exposure baked at various temperatures for $10 \mathrm{~min}$. Finally, the films were developed with $0.238 \mathrm{wt} \%$ TMAHaq at room temperature. The dissolution rates were estimated by the change in film thickness before and after development.

Figure 4 exhibits the effect of PEB temperature on the dissolution rate of the exposed and unexposed films. The dissolution rate of the exposed area remarkably decreases with increasing the PEB temperature compared to that of the unexposed area. The difference of the dissolution rates between both areas reaches to 300 times at $190{ }^{\circ} \mathrm{C}$.

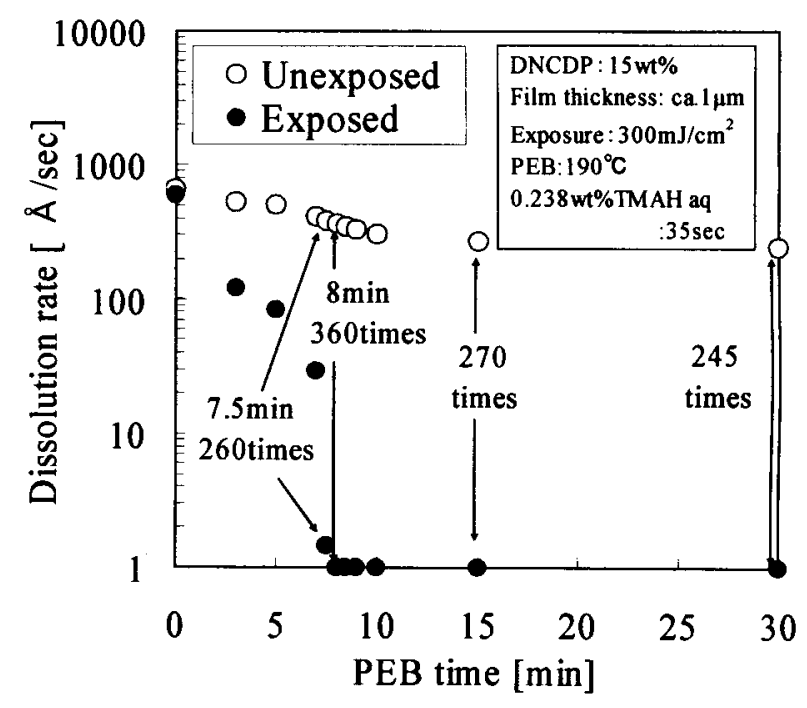

Figure 5. Effect of PEB time at $190{ }^{\circ} \mathrm{C}$ on the dissolution rate of the exposed and unexposed 1.0 $\mu \mathrm{m}$ PAA film containing $15 \mathrm{wt} \%$ DNCDP. 
Next, the effect of the PEB time on the dissolution rate was investigated at $190{ }^{\circ} \mathrm{C}$ in a similar manner (Figure 5). The high dissolution contrast is obtained with the PEB time ranging from 7.5 to $30 \mathrm{~min}$. The largest dissolution contrast is attained for the PEB time of $8 \mathrm{~min}$.

To make clear the relationship between the dissolution rate and the degree of imidization of PAA, the reaction was monitored by FT-IR spectroscopy. The degree of imidization of PAA in the solid phase was estimated by using two characteristic absorptions corresponding to the C$\mathrm{N}$ stretching of the imide group $\left(1381,1385 \mathrm{~cm}^{-1}\right)$ and the $\mathrm{C}-\mathrm{O}$ stretching of a phenyl ether comparing with those of thermally imidized PI cured at $350{ }^{\circ} \mathrm{C}$ for $1 \mathrm{~h}$ in air.

Imidization results are represented as normalized conversion values from PAA prebaked at $120{ }^{\circ} \mathrm{C}$ into PI fully cured at $350{ }^{\circ} \mathrm{C}$. The results are shown in Figure 6, where the PEB temperature is $190{ }^{\circ} \mathrm{C}$. The high dissolution contrast is obtained when the degree of imidization is over $60 \%$ in the exposed area and the difference of the degree of imidization between the exposed and unexposed areas is around $20 \%$.

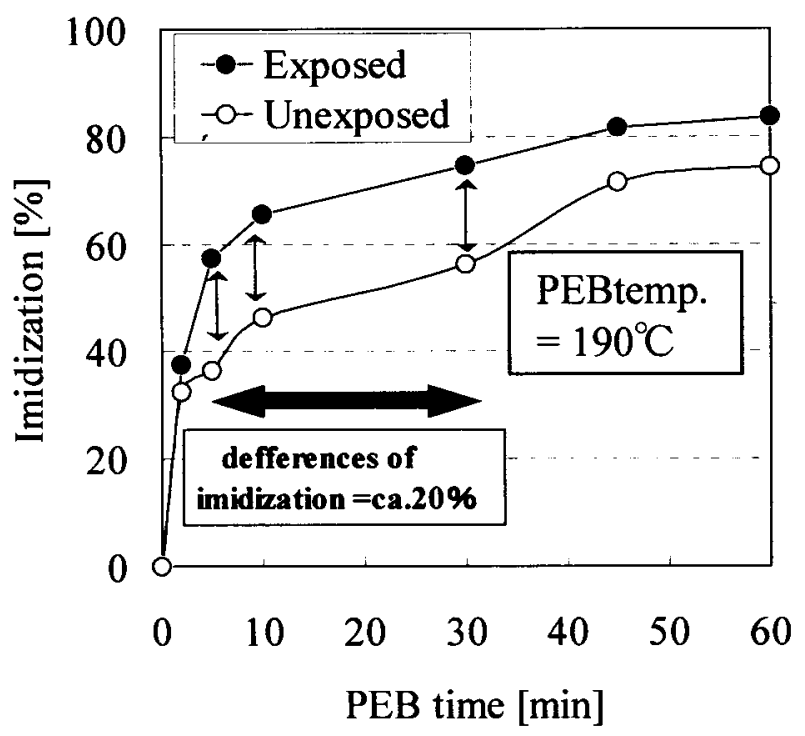

Figure 6. Effect of PEB time at $190{ }^{\circ} \mathrm{C}$ on the degree of imidization of $1.0 \mu \mathrm{m}$ PAA film containing $15 \mathrm{wt} \%$ DNCDP in both exposed and unexposed areas.

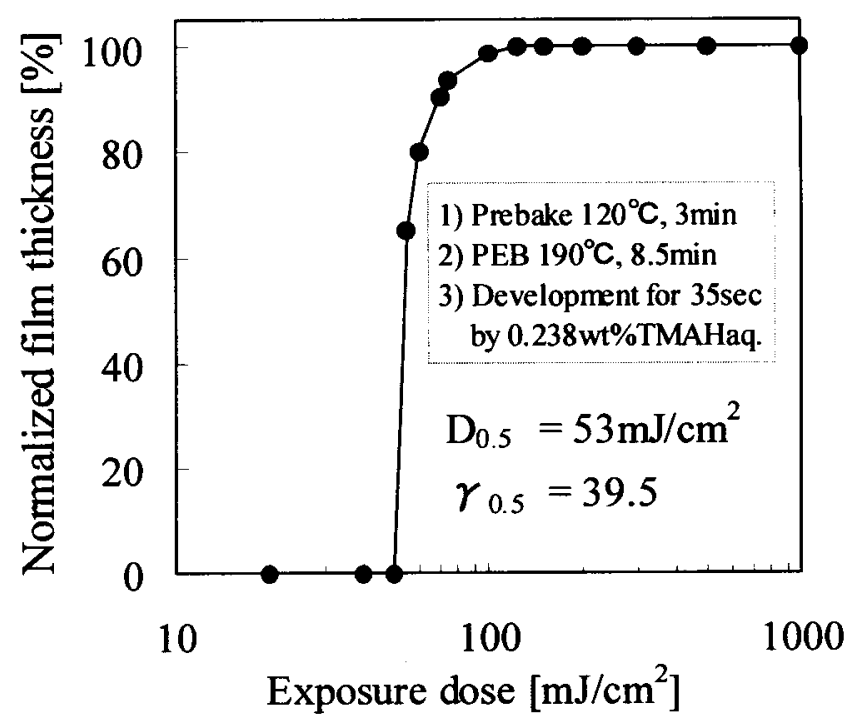

Figure 7. Characteristic photosensitivity curve of PSPI consisting of $85 \mathrm{wt} \%$ PAA and $15 \mathrm{wt} \%$ DNCDP in $1.0 \mu \mathrm{m}$ film thickness.

Based on these preliminary optimization studies, a photosensitive polymer PSSAPI consisting of PAA (85 wt\%) and DNCDP (15 wt\%) was formulated. The photosensitivity curve of a film $1.0 \mu \mathrm{m}$ thick is shown in Figure 7 (PEB treatment was conducted at $190{ }^{\circ} \mathrm{C}$ for $8.5 \mathrm{~min}$ and developed with $0.238 \mathrm{wt} \%$ TMAHaq). This resist system reveals the photosensitivity $\left(D_{0.5}\right)$ of 53 $\mathrm{mJ} / \mathrm{cm}^{2}$ and the contrast $\left(\gamma_{0.5}\right)$ of 39.5 with i-line exposure. This PSSAPI is more sensitive and has a higher contrast compared to those of the previously evaluated PSPI ( BPDA/ODA-type; $\mathrm{D}_{0.5}$ $=220 \mathrm{~mJ} / \mathrm{cm}^{2}: \gamma_{0.5}=11.7$ ) because of its high transparency at $\mathrm{i}$-line region. ${ }^{6}$

Figure 8 represents the SEM image of $1.05 \mu \mathrm{m}$ resist film exposed with i-line of $300 \mathrm{~mJ} / \mathrm{cm}^{2}$, post exposure baked at $190{ }^{\circ} \mathrm{C}$ for $8 \mathrm{~min}$, developed with $0.238 \mathrm{wt} \%$ TMAHaq at room temperature, and rinsed with water. A clear negative-tone image with a $6 \mu \mathrm{m}$ featured line and space resolution was obtained. 


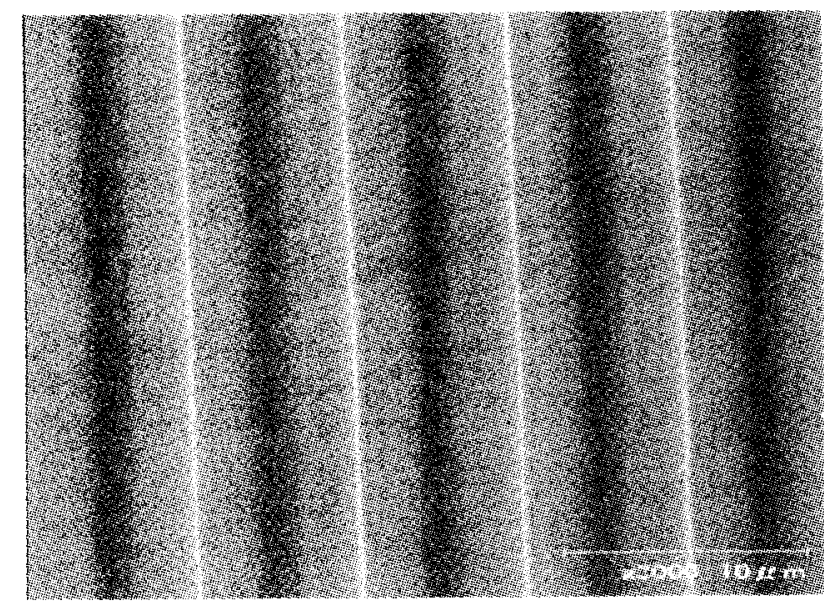

Figure 8. SEM image of PSSAPI pattern based on $75 \mathrm{wt} \%$ PAA and $25 \mathrm{wt} \%$ DNCDP. The lithographic conditions were as followed; 13 wt $\%$ solid content solution in DMAc spincoated; prebaked at $120{ }^{\circ} \mathrm{C}$, for $3 \mathrm{~min}$; exposed $300 \mathrm{~mJ} / \mathrm{cm}^{2}$ in i-line; PEB at $190{ }^{\circ} \mathrm{C}$ for $8 \mathrm{~min}$ (film thickness $=1.2 \mu \mathrm{m}$ ) ; development with $0.238 \mathrm{wt} \%$ TMAHaq. for $2.5 \mathrm{~min}$ at room temperature (film thickness $=1.05 \mu \mathrm{m}$ ).

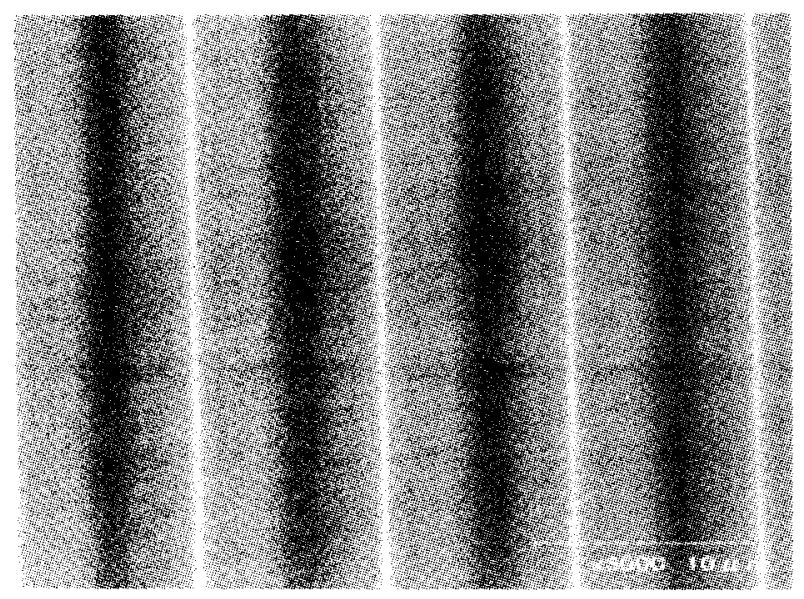

Figure 9. SEM image of PI pattern cured at $200{ }^{\circ} \mathrm{C}$ for $30 \mathrm{~min}$ (film thickness $=1.0 \mu \mathrm{m}$ ).
Figure 9 shows the SEM image of $1.0 \mu \mathrm{m}$ resist film cured at $200{ }^{\circ} \mathrm{C}$ for $30 \mathrm{~min}$ after above treatment. The loss of the film after curing is small (ca. $5 \% 1$ loss of film thickness).

\section{Conclusions}

A negative-type, alkaline-developable, and high sensitive PSPI (PSSAPI) was developed. The semi-alicyclic PAA was prepared from CBDA and ODA. The semi-alicyclic PAA was a high transparency in the $365 \mathrm{~nm}$ region. The PSSAPI film consisting of $85 \mathrm{wt} \%$ PAA and $15 \mathrm{wt} \%$ DNCDP exhibited the high photosensitivity and contrast $53 \mathrm{~mJ} / \mathrm{cm}^{2}, 39.5$, respectively, to $365 \mathrm{~nm}$ light exposure. The semi-alicyclic PAA containing $25 \mathrm{wt} \%$ DNCDP produced a clear negative-tone image with $6 \mu \mathrm{m}$ features. Subsequently, this pattern was converted into the corresponding PI upon thermal treatment at $200{ }^{\circ} \mathrm{C}$ for $30 \mathrm{~min}$. This methodology to develop a high sensitive PSPI that has a high contrast will provide a more effective and well-rounded pattering formation compared to another methods that require the multi-steps syntheses of PSPI.

\section{References}

1. "Polyimides fundamentals and applications", $M$. K. Ghosh, and K. L. Mittal, Ed., Marcel Dekker: New York, 1996.

2. "Photosensitive Polyimides fundamentals and applications" K. Horie, and T. Yamashita, Ed., Technomic, Lancaster, 1995.

3. Y. Watanabe, Y. Shibasaki, S. Ando, and M. Ueda, Polym. J., 37, 270 (2005).

4. Y. Watanabe, K. Fukukawa, Y. Shibasaki, and M. Ueda, J. Polym. Sc: Part A. Polym. Chem., 43, 593 (2005).

5. K. Sakayori, Y. Shibasaki, and M. Ueda, Polym. J., 38, 1189 (2006).

6. K. Fukukawa, Y. Shibasaki, and M. Ueda, Polym. Adv. Technol. 17,131-136 (2006)

7. A. Mochizuki, T. Teranishi, and M. Ueda, Macromolecules, 28, 365 (1995). 